\title{
La invisibilidad como problema: primeras aproximaciones a la situación de las niñas y los niños durante la política de confinamiento por la pandemia de COVID-19 en Argentina
}

\author{
María Jimena Mantilla \\ Consejo Nacional de Investigaciones Científicas y Técnicas (CONICET) \\ mantillamariajimena@gmail.com
}

Fecha de recepción: 11-6-2020

Fecha de aceptación: 30-6-2020

\section{Resumen}

El presente trabajo tiene por objetivo analizar la invisibilidad de la infancia tomando como disparador el clima social respecto a dicho tramo de edad durante la gestión en Argentina de la pandemia mundial de la COVID-19. Concretamente, se describe y se analiza la concepción de las infancias en la regulación de las salidas para los más chicos en el marco de las medidas de confinamiento de la población. El artículo sugiere que la invisibilidad de las criaturas excede la política sanitaria durante la actual emergencia y responde a las imágenes arraigadas a nivel social que apelan tanto al heroísmo como a la peligrosidad de los niños y las niñas.

Palabras clave: infancia; invisibilidad; confinamiento; Argentina

Abstract. Invisibility as a problem: First approaches to the situation of children under the COVID-19 pandemic confinement policy in Argentina

The aim of this article is to analyze the invisibility of childhood taking as a starting point children's social climate during the management in Argentina of the global COVID-19 pandemic. Specifically, the paper describes the ways in which the notion of childhood has been shaped through the regulation of outdoor activities for children in the context of population lockdown measures. The paper suggests that the invisibility of childhood has exceeded health policy during the current crisis and responds to socially embedded images that appeal to both the heroism and dangerousness of children.

Keywords: childhood; invisibility; confinement; Argentina

\section{Sumario}

1. Introducción

2. La política sanitaria de cuarentena obligatoria: un recorrido sobre las promulgaciones oficiales y de los medios de comunicación
3. A modo de cierre

Referencias bibliográficas 
Pienso que este contexto transparentó la invisibilidad de los niños. Yo pienso que hay mucha gente desde el estado, sobre todo cuando ocurre la primera reunión con UNICEF, que ocurre con la segunda prórroga de la cuarentena, cuando salen los medios a decir que por fin va a haber una reunión con UNICEF, ahí pareció... Es como que fueron políticamente correctos porque el tema de la infancia estaba comenzando a girar por ahí, pero si vos mirás bien es como que se quedaron tranquilos con esto y no hicieron nada. Pero esto lo digo sin entrar en juicio de valor hacia nadie, esto no es de color político, esto habla de nuestra cultura, no tiene que ver con algo consciente, al contrario, desde el plano consciente tuvieron la delicadeza de consultar, pero en verdad el niño es invisible, totalmente invisible.

(Fragmento de entrevista con especialista en crianza, mayo de 2020)

\section{Introducción}

La cita anterior refleja el problema que aborda este artículo: la invisibilidad de la infancia tomando como disparador el clima social respecto a los niños y las niñas durante la gestión en Argentina de la pandemia mundial de COVID-19 ${ }^{1}$.

El pasado 19 de marzo el presidente de la Nación anunciaba el comienzo del aislamiento social preventivo y obligatorio para todo el territorio argentino a partir del día 20 de marzo. Las clases en todos los niveles educativos ya se habían suspendido cuatro días antes, junto a los espectáculos deportivos y artísticos. Desde aquel momento, los niños y las niñas quedaron confinados en sus casas.

El objetivo de este trabajo es analizar la concepción de la infancia que subyace en la invisibilidad de las niñas y los niños durante la pandemia de COVID-19, tanto en las políticas sanitarias implementadas como en la arena social. Si bien la medida sanitaria de aislamiento social preventivo y obligatorio, efectiva y necesaria para ralentizar la curva de contagios por COVID-19, pone en jaque otros derechos y necesidades, hay grupos prioritarios, como la infancia, que deberían ser contemplados sin por eso suspender o debilitar las decisiones tomadas. Con la invisibilidad de este tramo de edad me refiero a la ausencia de una real consideración de este grupo poblacional como actor político de peso en la arena social.

Los niños y las niñas constituyen un grupo particularmente vulnerable al encierro, en tanto se encuentran en pleno proceso de desarrollo físico, psíquico y social. El aire libre y el movimiento son necesidades fisiológicas en la primera infancia e impedirlas puede tener efectos sin precedentes. Asimismo, la existencia de una enfermedad que no nos deja salir de casa por tiempo

1. Sin duda que el encierro como problema refleja la situación de solo algunos tipos de infancias en la Argentina. Los niños y niñas en situación de pobreza atraviesan otras vulnerabilidades y su cumplimiento de la cuarentena se ve comprometido por factores habitacionales y la falta de acceso a servicios básicos como el agua potable. 
indeterminado es una máxima difícilmente tolerable para una criatura en desarrollo que está formando sus imágenes del mundo. Esto tampoco puede dejarse librado al azar y hubiese ameritado un tratamiento riguroso por parte de la sociedad - y en especial de los tomadores de decisiones - desde el inicio de la pandemia. Por el contrario, más allá de la posterior flexibilización de salidas recreativas para las niñas y los niños en algunas ciudades del país ${ }^{2}$, en el plano social este olvido de la infancia se amplifica en la intolerancia de vecinos y en las actitudes de discriminación en referencia a la presencia de la niñez en las calles. ¿Qué nos dice de las ideas y de las creencias sociales acerca de los más chicos el hecho de que no se hayan considerado como actores sociales de peso en la discusión, la implementación y el posterior cumplimiento y regulación de las medidas necesarias para contener la pandemia en Argentina?

El artículo se inscribe en los estudios sociales de la infancia (James et al., 1998; Jenks, 1996; entre otros), en particular en la línea de trabajo que problematiza la agencia social de los niños y las niñas y su estatus en las sociedades contemporáneas (Pavez Soto, 2012).

Para el análisis se utilizaron mayoritariamente fuentes secundarias como las notas periodísticas publicadas en los principales portales de noticias del país. El criterio de selección de las notas fueron los buscadores «infancia y aislamiento" e «infancia y COVID-19». Se relevaron 30 notas que fueron analizadas mediante la técnica de análisis de contenido. De modo complementario se utilizaron las publicaciones en las redes sociales (en particular de un grupo de crianza de cuyas acciones hago un seguimiento continuo por ser fuente de mi trabajo de investigación) y una entrevista con una informante clave, especialista en temas de cuidado y desarrollo infantil, cuyas palabras se citan en el epígrafe. Dado que la recolección de los datos es incipiente, este artículo es solo una reflexión preliminar de la temática. A continuación efectúo un análisis acerca de las imágenes de las criaturas que circularon en los medios periodísticos y de las políticas y promulgaciones estatales que buscaron dar respuesta a la problemática de las salidas recreativas infantiles.

\section{La política sanitaria de cuarentena obligatoria: un recorrido sobre las promulgaciones oficiales y de los medios de comunicación}

Si se contemplan los efectos de ralentización de la curva de contagios, en Argentina la medida de aislamiento social preventivo y obligatorio ha sido tomada en forma temprana y oportuna. El Gobierno nacional en coordinación con los gobiernos provinciales ha instrumentado una serie de mejoras en el sistema de salud. La medida sanitaria ha permitido la inversión y la prepara-

2. Las diversidades de experiencias infantiles respecto a los efectos del confinamiento y la posibilidad de realizar salidas recreativas varían sin duda según si se trata de ciudades pequeñas, grandes metrópolis o espacios rurales. En el presente trabajo se estudia esta problemática a partir de un análisis de la situación en la ciudad de Buenos Aires y en el Gran Buenos Aires. Asimismo, los efectos de la problemática del encierro varían según se trate de sectores medios y altos o populares. 
ción de los insumos que necesita el sector para funcionar de forma más acorde con los requerimientos de equipamiento, camas y personal de salud para atender casos graves ante una eventual disparada en el número de casos positivos.

La pandemia ha cambiado la dinámica en que las niñas y los niños se están desarrollando. A más de dos meses de inicio del confinamiento es imposible no pensar en los efectos sociales, emocionales y fisiológicos de esta medida. ¿Cómo procesan los más chicos lo que está ocurriendo? ¿Con qué herramientas comunicacionales contamos los adultos para ayudarlos a transitar por esta situación sin aumentar los miedos a las enfermedades ni las fobias al contacto, teniendo en cuenta que por su edad se encuentran en pleno proceso de constitución de sus subjetividades? Sin duda, el aislamiento afecta a toda la sociedad de diversas maneras, pero cuando pensamos en personas que se encuentran en plena constitución de su personalidad los daños podrían ser más penetrantes y duraderos.

El vacío de estos interrogantes en la arena pública, sumado a la ausencia de una política sanitaria que dé respuesta a los mismos (mediante flexibilizaciones seguras que contemplaran las necesidades de la infancia desde el inicio), son parte del recorrido de este trabajo, donde se describen los posicionamientos políticos según las fuentes periodísticas y los documentos oficiales.

En Argentina, a un mes de comenzada la cuarentena, el Gobierno se reunió con representantes de UNICEF, quienes plantearon la necesidad de buscar alternativas al aislamiento de los niños y las niñas. El organismo ofreció datos acerca de una encuesta implementada entre el 8 y el 15 de abril del corriente año (Encuesta de Percepción y Actitudes de la Población: Impacto de la pandemia y las medidas adoptadas por el gobierno sobre la vida cotidiana de niñas, niños y adolescentes), que brinda información acerca de la situación económica de las familias, la violencia de género y la percepción sobre la cuarentena, entre otras variables, pero que nada dice acerca del encierro en la infancia. Asimismo, cuando se contemplan directamente las percepciones de los encuestados se hace referencia a los adolescentes, pero no a los niños ni a las niñas. De la reunión con UNICEF no surgieron resultados precisos respecto a la pronunciación de una estrategia política que diera respuesta a esta problemática.

Otros organismos oficiales emitieron también documentos que pusieron el foco en los efectos del aislamiento en la salud mental de las criaturas. Es el caso del Ministerio de Salud de la Nación, que el primero de abril lanzó un documento con recomendaciones para acompañar y contener a niños, niñas y adolescentes. En el mismo se aborda cómo explicarles lo que está ocurriendo según las edades, cómo transmitir normas de cuidado e higiene, cómo organizar rutinas hogareñas que incluyen la educación virtual, entre otras dimensiones centrales de la experiencia de la cuarentena, pero no hay información acerca del encierro en sí mismo como problema o de la necesidad de flexibilizarlo (Ministerio de Salud, 2020).

Lo mismo puede decirse de la Sociedad Argentina de Pediatría, que en su informe tampoco advierte acerca de los daños del encierro ni de la necesidad de atenuarlos mediante salidas recreativas (SAP, 2020). 
El problema del confinamiento infantil, en términos políticos y a riesgo de que la perspectiva de flexibilizar la cuarentena quedara atrapada en una polaridad partidaria, fue tratado por la formación opositora al gobierno nacional, que presentó un proyecto de ley para aliviar el encierro de los más chicos (Chavez, 2020). Los argumentos que impulsaron el proyecto ponen el foco en la crítica a la pasiva aceptación social del aislamiento infantil. Según la legisladora que impulsó la iniciativa: «Hay una visión edulcorada de que los niños están en la casa jugando y mirando la tele», sin tener en cuenta que:

Sobre todo los más pequeños necesitan luz solar, movimiento, dar un paseo al menos por día que, además, resulta vital si se considera que la Argentina ocupa el segundo puesto de la región en obesidad en niños menores de cinco años y se estima que uno de cada tres niños en edad escolar padecen sobrepeso u obesidad y que el sedentarismo y la mala alimentación son las dos causas centrales de esta otra epidemia. (Chavez, 2020)

El tema de las salidas recreativas para disminuir los efectos del encierro fue abordado públicamente por el presidente a más de un mes del comienzo de la cuarentena. El mandatario, durante una conferencia de prensa, habilitó que "cualquier persona salga una vez al día, durante una hora, en un radio de 500 metros de su casa", medida que quedó ad referendum de las provincias o de los municipios. "Los niños pueden salir acompañados por sus padres, los adolescentes, solos», sostuvo, para luego resaltar: "Hay que tener en claro que esto significa exponerse mayormente al virus» ("Coronavirus en la Argentina...», 2020).

La aclaración final del presidente respecto a la exposición al virus visibiliza un miedo social frecuente que envuelve a aquellas familias que, más allá de las regulaciones políticas, evitan salir a dar una vuelta, pese a que las recomendaciones científicas informan acerca de que el riesgo de transmisión del virus es menor cuando se realizan actividades al aire libre, siempre que se tomen las medidas de prevención adecuadas.

El discurso del presidente generó expectativas acerca de una regulación de salidas en todo el territorio argentino, sin embargo, el mandatario dejó librada la decisión de cómo llevar adelante la medida de salidas recreativas en cada jurisdicción. En consecuencia, como medida para evitar una expansión de los contagios, los grandes conglomerados urbanos decidieron no implementarla.

No obstante, a mediados de mayo, el Gobierno de la ciudad de Buenos Aires instrumentó una estrategia de flexibilización de la cuarentena que, entre otras cosas, permitió que los niños y las niñas realizaran salidas recreativas los sábados y domingos por una hora. Una medida parcial que dejó afuera las necesidades de movimiento y aire libre de los otros cinco días de la semana. La provincia de Buenos Aires, sin embargo, continuó sin instrumentar salidas recreativas como medida para paliar los efectos del encierro (Cibeira, 2020).

Más allá de las privaciones causadas por el aislamiento, los pequeños tampoco fueron bien recibidos cuando acompañaban a sus progenitores a los comercios. El caso de un conocido actor al que le impidieron entrar a un 
supermercado por estar con su hija de 3 años dio cuenta de esta situación en la arena pública. A continuación reproducimos un fragmento de una nota periodística que releva este hecho en otros múltiples casos:

«Los chicos afuera»; «disculpe mami, pero tiene que dejar a la nena en casa» o «yo solo cumplo con mi deber de informarle de que los niños no pueden circular» son algunas de las respuestas que llegaron a este suplemento de diversos agentes del orden público y privado que supuestamente resguardan la seguridad de todos. (Monfort, 2020)

Comerciantes que niegan los derechos básicos y que asustan a las niñas y a los niños son parte de un escenario social actual que combina la invisibilidad de la infancia como sujeto de derechos con una ya previamente instalada intolerancia social a la presencia de los más chicos en el espacio público.

La intolerancia a la presencia de la niñez en las calles es una expresión directa de las imágenes de peligrosidad que circulan sobre este colectivo. Por ejemplo, en un programa televisivo una psicóloga consultada declaraba lo siguiente: «Están muy tristes, muy deprimidos. Pero también es un riesgo salir a la calle. Hay que tener resguardos. Un niño es desafiante al límite por naturaleza. Pero la rebeldía lo pone en riesgo» ("Chicos en cuarentena...», 2020).

La idea de que los críos son rebeldes e incontrolables supone que no pueden cumplir las normas de distancia social e higiene requeridas para evitar el contagio. En consecuencia, son peligrosos. Así se justifica la negativa a dejarlos participar en las pocas actividades de la vida cotidiana que quedaron sin interrupciones durante la cuarentena.

La contracara de la invisibilidad y la peligrosidad es la figura del heroísmo, sostenida a partir de la creencia de que los niños y las niñas «se adaptan a todo", por lo tanto aceptan el aislamiento sin mayores consecuencias. Las apelaciones al heroísmo de los pequeños se evidenciaron en diversas intervenciones sociales; por ejemplo: la Cámara Argentina de la Industria del Juguete convocó a realizar un aplauso colectivo desde las casas para «reconocer a los más chicos que vienen llevando la cuarentena de modo ejemplar»:

Hoy sábado 18 de abril a las 18:00 horas nos unimos en \#APLAUSOALOS CHICOS por su capacidad de adaptación, por su comprensión, por su paciencia. («Una iniciativa propone aplaudir...», 2020)

En la línea de reconocer a la infancia a partir de una mirada que oscila entre darle protagonismo y ubicarla bajo el manto del heroísmo por soportar la cuarentena, se pueden ubicar dos intervenciones presidenciales. A través de las redes sociales el presidente sumó su apoyo a la campaña organizada por el Ministerio Tutelar que invitaba a los niños y niñas a dibujar para homenajear a los profesionales de la salud: «Sentate ya a dibujar que vas a estar haciendo un bien a quienes nos están cuidando, cuento con vos» («La campaña a la que se sumó...", 2020). 
Asimismo, en otro mensaje lanzado mediante las redes sociales los invitaba a mandarle dibujos que él mismo respondía. Si bien con ambos mensajes el Gobierno establece un reconocimiento a la infancia como un actor social, la efectividad de ese reconocimiento en época de pandemia depende, en primer lugar, de dar respuesta al problema del encierro.

En resumen, las ideas que circularon en la sociedad con motivo de la enfermedad de la COVID-19 pusieron de relieve dos imágenes sociales: los niños y las niñas son desafiantes al límite por naturaleza o por el contrario respetan prosaicamente la cuarentena y se adaptan fácilmente a ella.

\section{A modo de cierre}

En este artículo abordé la invisibilidad de la infancia como problema en el marco de la política sanitaria instrumentada para enfrentar la pandemia de la COVID-19. La ausencia de una política temprana de flexibilización del aislamiento en pos de considerar las necesidades fisiológicas de la niñez mostró una serie de imágenes sociales que circulan acerca de los más chicos. Los niños y las niñas han sido tradicionalmente representados como más cercanos a la naturaleza que los adultos, por un lado a partir de su salvajismo y su falta de civilización, pero también por su pureza e inocencia, supuestamente no contaminada por la influencia de la sociedad (James et al., 1998; Lupton, 2012; Gaitán, 2006) ${ }^{3}$. La noción de peligrosidad que refleja la discriminación que sufre la infancia en los comercios, sumada a la figura del heroísmo como modo de representar socialmente la tolerancia y la aceptación de la cuarentena por parte de los pequeños cristalizan representaciones poco reales de ellos que les restan agencia, capacidad de interlocución y que, en definitiva, anulan su propia condición de sujetos de derechos.

\section{Referencias bibliográficas}

Chavez, V. (2020). «La cuarentena de los más chicos: "Se debe terminar con la visión edulcorada de que los niños están en casa jugando"». Infobae (25 de abril). Recuperado de <https://www.infobae.com/coronavirus/ 2020/04/26/la-cuarentena-de-los-mas-chicos-se-debe-terminar-con-lavision-edulcorada-de-que-los-ninos-estan-en-casa-jugando/>.

"Chicos en cuarentena: ¿Cómo impacta el aislamiento en los niños y niñas?». Todo Noticias (23 de abril de 2020). Recuperado de <https://www.youtube. $\mathrm{com} /$ watch? $\mathrm{v}=\mathrm{xbgWxBnVYQM>}$.

Cibeira, F. (2020). «Más negocios, running nocturno y una idea de protocolo para volver a las aulas». Página/12 (4 de junio). Recuperado de <https://

3. La homologación de los niños con la naturaleza es comparable a la de las mujeres. En esta línea, la asociación entre naturaleza, subjetividad, emociones y condición femenina, opuesta a la ligazón entre cultura, objetividad, razón y masculinidad, ha sido largamente señalada por los estudios sociales de la ciencia y la epistemología feministas (Fox Keller, 1985; Laqueur, 1990; Haraway, 1991; entre otros). 
www.pagina12.com.ar/270170-mas-negocios-running-nocturno-y-unaidea-de-protocolo-para-v>.

"Coronavirus en la Argentina: qué dijo Alberto Fernández sobre la salida de niños y adolescentes». La Nación (25 de mayo de 2020). Recuperado de $<$ https://www.lanacion.com.ar/politica/coronavirus-argentina-que-dijoalberto-fernandez-salidas-nid2358323>.

Fox Keller, E. (1985). Reflections on Gender and Science. New Haven: Yale University Press.

Gaitán, L. (2006). Sociología de la infancia. Madrid: Síntesis.

Haraway, D. (1991). Simians, Cyborgs, and Women: The Reinvention of Nature. Nueva York: Routledge.

James, A.; Jenks. C. y Prout, A (1998). Theorizing Childhood. Cambridge: Polity Press.

Jenks, C. (1996). Childhood. Londres: Routledge.

"La campaña a la que se sumó Alberto Fernández: "Ponete a dibujar"». La Nación (13 de abril de 2020). Recuperado de <https://www.lanacion.com. ar/politica/la-campana-se-sumo-alberto-fernandez-ponete-nid2353876>.

Laqueur, T. (1990). Making Sex: Body and Gender from the Greeks to Freud. Cambridge: Harvard University Press.

Lupton, D. (2012). «Infant embodiment and interembodiment: A review of sociocultural perspectives». Childhood, 20 (1), 37-50. $<$ https://doi.org/10.1177/0907568212447244>

Ministerio de SALUd de la Nación (2020). Recomendaciones sobre salud mental para la población de niños, niñas y adolescentes por la pandemia covid19. Buenos Aires: Ministerio de Salud de la Nación Argentina. Recuperado de <http://www.msal.gob.ar/images/stories/bes/graficos/0000001886 cnt-covid-19-recomendaciones-salud-mental-ninos-ninas-adolescentescontexto-pandemia.pdf>.

Monfort, F. (2020). «El efecto de la cuarentena por coronavirus en la infancia». Página/12 (24 de abril). Recuperado de <https://www.pagina12.com. ar/261486-el-efecto-de-la-cuarentena-por-coronavirus-en-la-infancia>.

Pavez Soto, I. (2012). «Sociología de la infancia: Las niñas y los niños como actores sociales». Revista de Sociología, 27, 81-102.

Sociedad Argentina de Pediatría (2020). El estado emocional de laslos niñaslos y adolescentes a más de un mes del Aislamiento Social, Preventivo y Obligatorio. Buenos Aires: SAP. Recuperado de <https://www.sap.org.ar/ uploads/archivos/general/files_estado-emocional-cuarentena-present-04-20 _1588036236.pdf >.

«Una iniciativa propone aplaudir hoy a las 18 horas a los niños por quedarse en casa». Infobae (18 de abril de 2020). Recuperado de <https://www. infobae.com/tendencias/2020/04/18/una-iniciativa-propone-aplaudir-hoya-las-18-horas-a-los-ninos-por-quedarse-en-casa/>. 
María Jimena Mantilla es doctora en Ciencias Sociales (UBA), magíster en Investigación en Ciencias Sociales (UBA) y licenciada en Trabajo Social (UBA). Investigadora adjunta del Consejo Nacional de Investigaciones Científicas y Técnicas (CONICET) y del Instituto de Investigaciones Gino Germani de la Universidad de Buenos Aires, Facultad de Ciencias Sociales. Actualmente investiga temas de crianza, maternidades e infancia.

María Jimena Mantilla holds a PhD in Social Sciences, a Master of Social Sciences and a Licentiate of Social Work from the Autonomous University of Barcelona (UBA). She is an associate researcher at the National Council for Scientific and Technical Research (CONICET) and the Gino Germani Research Institute of the University of Buenos Aires, Social Sciences School. Her current research lines focus on topics related to parenting, maternity and childhood. 